\title{
PLASTIC SURGERY
}

\section{Scar wars}

\author{
E Möller, ${ }^{1}$ R Martinez, ${ }^{2}$ H Rode, ${ }^{2}$ S Adams ${ }^{1}$ \\ ${ }^{I}$ Division of Plastic and Reconstructive Surgery, Red Cross War Memorial Children's Hospital, University of Cape Town, \\ South Africa \\ ${ }^{2}$ Division of Paediatric and Burn Surgery, Red Cross War Memorial Children's Hospital, University of Cape Town, \\ South Africa
}

Corresponding author: Dr Ernst Möller (ernstmoller_10@hotmail.com)

Background: Burn scars are common in the paediatric population. When involving the face, it diminishes quality of life. Ablative fractional laser (AFL) therapy is becoming the preferred choice for established scars due to its greater potential depth for thermal injury $(4 \mathrm{~mm})$, which leads to photothermolysis with subsequent neocollagenesis and collagen fibre realignment and remodelling. Combined with small z-plasties and topical steroids, it has been proven to: flatten and decrease the volume of scars, increase pliability and decrease pruritus and erythema. The purpose of the case series was to determine the clinical significance of a single session of AFL therapy, combined with small z-plasties and topical steroids on facial scars post burn injury.

Methods: Four cases of paediatric facial scarring post burns were selected to undergo a single treatment of AFL therapy, accompanied by small z-plasties and topical steroids. Modified Vancouver Scar Scores (MVSS) pre- and postoperatively at 3 and 6 months were evaluated.

Results: Improvement of all components of the MVSS was achieved after 6 months, with major improvement in scar pliability and symptomatology. The mean MVSS improved from 14 (range 12-16) preoperatively to 5 and 5.5 respectively at 3 and 6 months postoperatively. Non-parametric analysis with Friedman Two-Way ANOVA by Rank showed a statistical significance between the pre- and postoperative MVSS ( $\mathrm{p}=0.024)$.

Conclusion: AFL should form an integral part of the burn scar armamentarium.

Keywords: burn scars, paediatric population, ablative fractional laser

S Afr J Surg 2019;57(4)

http://dx.doi.org/10.17159/2078-5151/2019/v57n4a3021

\section{Introduction}

Paediatric facial burns are common in South Africa. In the Western Cape, facial burns account for $20 \%$ of the overall body surface affected. ${ }^{1}$ Even more alarming is that $40 \%$ of burns treated at our institution, Red Cross War Memorial Children's Hospital (RCWMCH), involved the head and neck region as single or multiple site burns. ${ }^{2}$

Major advances in acute burn care resuscitation and treatment has led to an increased survival rate. This has led to an increased population of patients with bad scarring. When confined to the face, scars produce significant morbidity and impair quality of life in several ways. They have a raised and vascular appearance, reduced pliability and can lead to possible debilitating contractures, intense pruritus and refractory pain. ${ }^{3}$

Treatment of scars, can be surgical or conservative, depending on the severity of patient signs and symptoms. ${ }^{4-7}$ Although surgical release remains the mainstay of treatment for contractures, ${ }^{8}$ laser therapy is becoming more popular. ${ }^{9,10}$

Ablative fractional laser (AFL) therapy is becoming the preferred choice for established scars, due to its greater potential depth for thermal injury (4 mm), which leads to photothermolysis with subsequent neocollagenesis and collagen fibre realignment and remodelling. ${ }^{11-13}$ Combining laser therapy with small z-plasties has proven to thin and soften scars, improve texture, flatten and decrease volume of scars, increase pliability and decrease pruritus and erythema and is a suitable alternative to scar excision. ${ }^{14}$

Due to lack of laser therapy outcomes for scars on the African continent, we decided to select suitable cases for a single session of ablative fractional laser therapy combined with small z-plasties and topical steroids, to assess its feasibility in the South African context.

\section{Methods}

Four cases of facial scarring post burns were selected to undergo a single session of ablative fractional carbon dioxide laser therapy with small tension relieving z-plasties and topical steroids at RCWMCH. All 4 cases sustained flame burns to the face and scalp. Three cases required early excision and split-thickness skin grafting (SSG) as definitive 
treatment. One case was treated with wound dressings only and healing by secondary intention.

The procedure was performed under general anaesthesia and consisted of the following four components:

1. Small tension relieving z-plasties for thick bands or contractures.

2. Ablative fractional carbon dioxide laser therapy utilising the Fractional, 10.600-nm wavelength $\mathrm{CO}_{2}$ laser (Lumenis UltraPulse, CPG and DeepFX hand pieces, Santa Clara, $C A)$ to burr columns of 600-1000 microns in size through the scars connecting with the underlying subcutaneous tissue, followed by a superficial therapy which creates 10-70 micron columns on the surface of the scars to flatten out irregularities.

3. Topical application of dexamethazone ( $8 \mathrm{mg}$ diluted to 10 millilitres with normal saline).

4. Petroleum jelly (emolient) coverage of the face post treatment.

The patients were followed up at 2 weeks for routine wound check and again at 3 and 6 months, to assess the MVSS (Table 1) by a qualified plastic surgeon and occupational therapist. The higher the MVSS, the greater the morbidity associated with the scar.

\section{Results}

The age of the children was four, eight, ten and eleven years respectively. The mean time period from injury till intervention was 6 years (range 3-10 years). All 4 patients underwent treatment and followed up as planned. There was no intraoperative or postoperative complications. Preoperative and postoperative MVSSs are depicted in Figure 1. The mean preoperative scar score was 14 , while the mean postoperative scar scores were 5 and 5.5 at 3 and 6 months respectively. Improvements in all components of the MVSS were seen, with major improvement ( $>50 \%$ reduction) especially in scar pliability and symptom relief (Figure 2). Non-parametric analysis with the Friedman Two-Way ANOVA by Rank was used to assess for clinical significance between the three timeframes. There was a statistically significant difference in the MVSS between the pre- and postoperative timeframes, $\chi^{2}(2)=7.429, p=0.024$.

All cases were asymptomatic in terms of pain and pruritus at 3 months, although 1 case had refractory pruritus at 6 months, but required less frequent medication as prior to the treatment.

\section{Discussion}

Laser therapy combined with small surgical releases as alternative to extensive scar excision, is not uncommon. Donelan et al. evaluated 57 patients with facial burn scars undergoing pulsed dye laser and small z-plasties and concluded that it provides a safe and effective way for

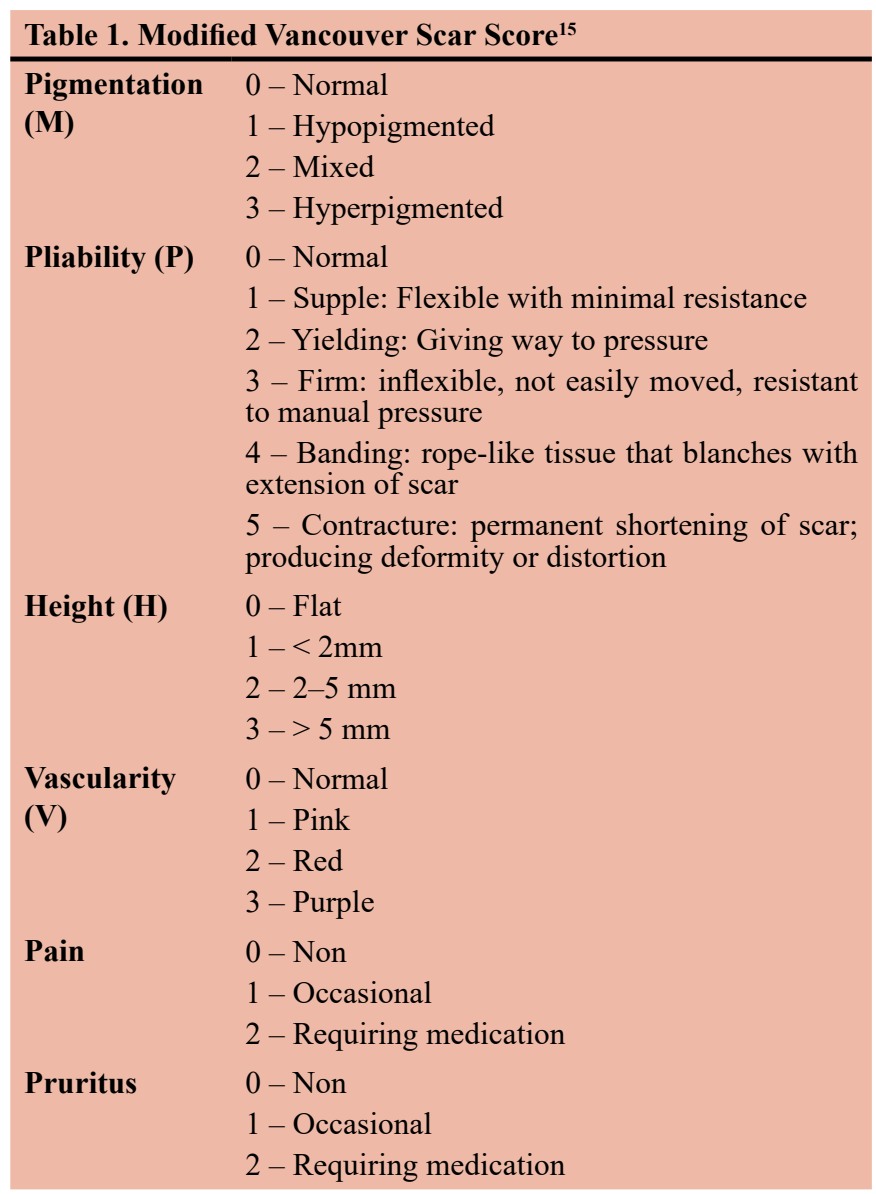

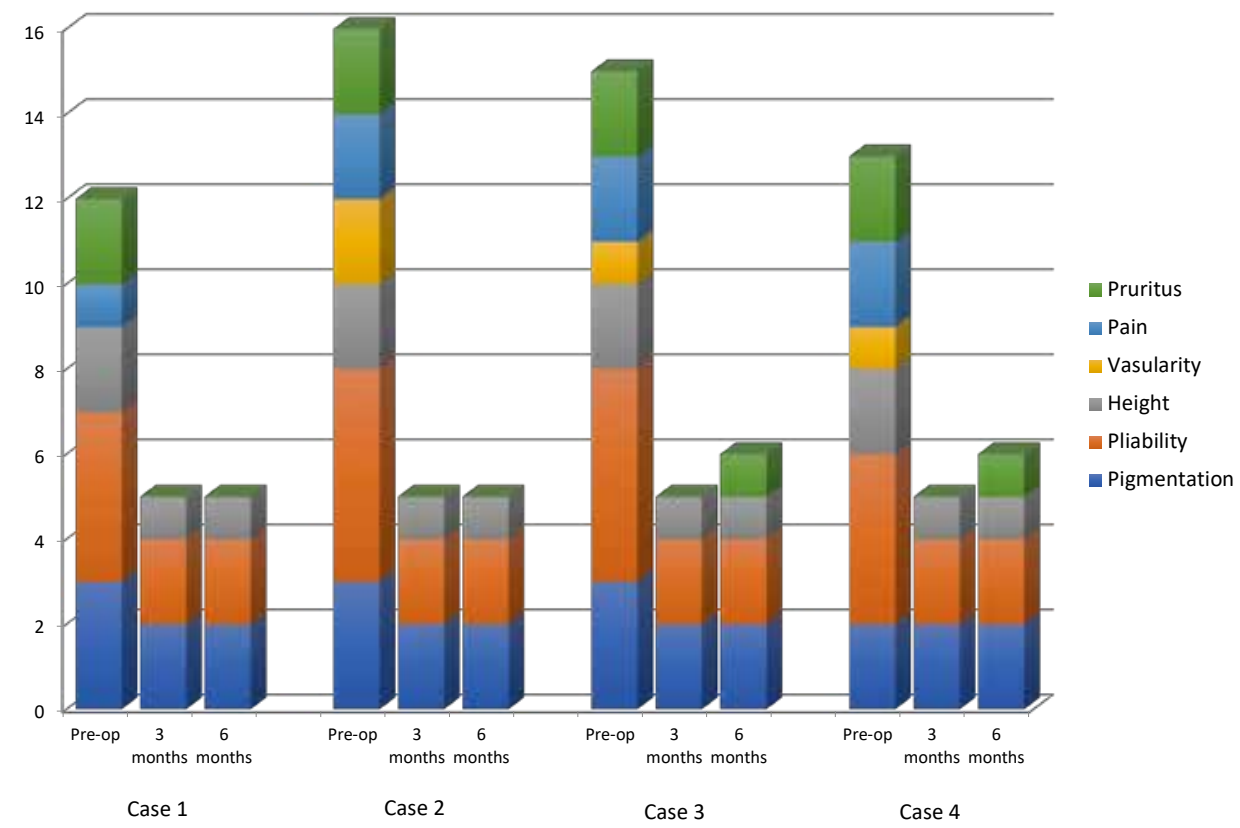

Figure 1 


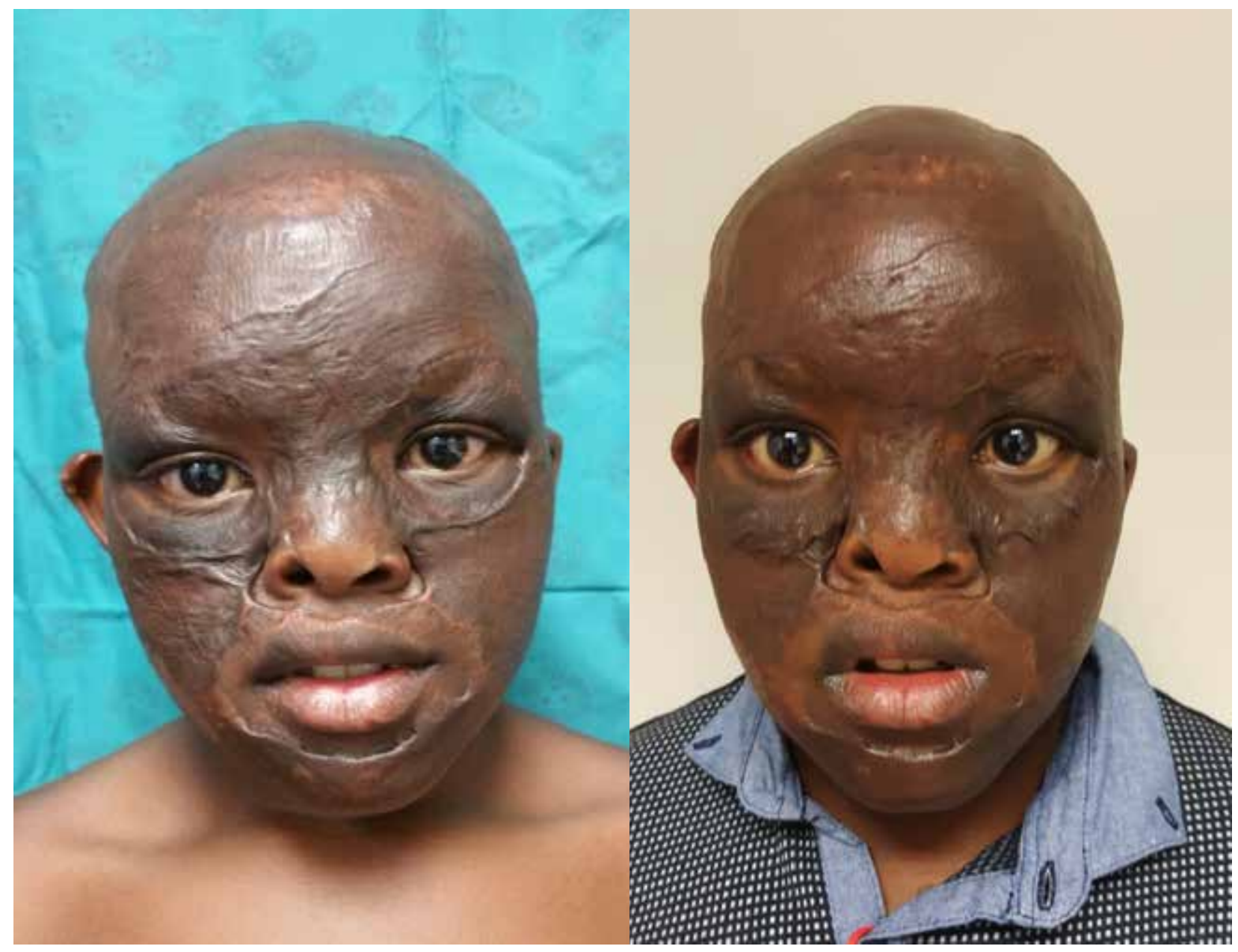

Figure 2

reversal of hypertrophic scarring and management of longstanding erythema and pruritus. ${ }^{14}$ With the advent of ablative fractional laser therapy, leading to greater efficacy and less downtime for scar treatments, ${ }^{16}$ multiple studies evaluated burn scars. Żądkowski et al. evaluated 47 children with hypertrophic burn scars and mean time from injury of 7.5 years, treated with ablative fractional $\mathrm{CO}_{2}$ laser therapy. ${ }^{17}$ As with our findings, they had improvement of all aspects of the VSS, especially scar pliability. Even though we combined z-plasties and topical steroid therapy with the AFL therapy, Hultman et al. have found similar results with AFL therapy alone. ${ }^{18} \mathrm{~A}$ major advancement in our case series was achieving significant VSS improvement and symptom relief after only one session, as all 4 of our cases had refractory pain and pruritus despite conventional scar management, i.e. physical therapy, compression dressings and silicon sheeting. This coincides with the findings of Issler-Fisher et al. which showed significant improvement in VSS and pain and pruritus scores after a single AFL treatment. ${ }^{19}$ Our case series also had patients of higher Fitzpatrick skin types. Three of our patients had scores of 5 and one of 4, compared to means of 2 - 4 as reported in other studies. ${ }^{18,20-22}$ Although the MVSS proved to be a valuable assessment tool of post burn scars, it fails to incorporate patient input and an additional tool will need to be utilised in future studies. Despite having combination procedures, none of our patients presented with any perioperative complications. A systematic review by Willows et al. of 51 observational studies, clinical trials and systematic reviews, highlighted the fact that laser therapies should be implemented in current burn scar protocols due to its significant benefits and minimal risk. ${ }^{23}$ Also worth mentioning is the gaining popularity of safe and successful early laser treatment of burn scars. ${ }^{24}$

\section{Conclusion}

This case series provides clinical evidence that a single ablative fractional laser treatment in combination with small z-plasties and topical steroids is effective and safe to significantly improve established scars multiple years post burn injury. Ablative fractional laser therapy has proven to be most effective due to its potential thermal injury depth, which leads to more effective collagen remodelling and realignment. Increased pliability of the scars and symptom relief after just one treatment, confirms the integral part laser therapy should play as part in the burn reconstruction armamentarium. This will alter current treatment protocols as careful consideration of rehabilitating scars instead of removing them with complex procedures will take priority. 


\section{Acknowledgements}

We would like to thank Professor Matthias Donelan from the Department of Plastic Surgery at Shriner's Hospital for Children in Boston, Massachusetts. His unwavering passion, guidance and expertise during his visit at RCWMCH, when these procedures were performed, have forever changed and improved our burn scar management protocols.

\section{Conflicts of interest \\ None}

\section{Ethics approval}

Ethical approval was obtained from the University of Cape Town HREC 863/2017.

\section{Orcid}

Ernst Möller https://orcid.org/0000-0002-3100-3314

\section{REFERENCES}

1. Parbhoo A, Quinette A, Grimmer-Somers K. A profile of hospital-admitted paediatric burns patients in South Africa. BMC Research Notes. 2010;3:165. PMID: 20540732 PMCID: PMC2893535 DOI: 10.1186/1756-0500-3-165

2. Teo AIC, Van As AB, Cooper J. A comparison of the epidemiology of paediatric burns in Scotland and South Africa. Burns. 2012;38:802-6. PMID: 22694871 DOI: 10.1016/j. burns.2012.04.010

3. Bock O, Schmid-Ott G, Malewski P, Mrowietz U. Quality of life of patients with keloid and hypertrophic scarring. Arch Dermatol Res. 2006;297:433-8. PMID: 16528552 DOI: 10.1007/s00403-006-0651-7

4. Berman B, Viera MH, Amini S, et al. Prevention and management of hypertrophic scars and keloids after burns in children. J Craniofac Surg. 2008;19:989-1006. PMID: 18650721 DOI: 10.1097/SCS.0b013e318175f3a7

5. Patel PA, Bailey JK, Yakuboff KP. Treatment outcomes for keloid scar management in the pediatric burn population. Burns. 2011;38:767-71. PMID: 22365616 DOI: 10.1016/j. burns.2011.11.007

6. Steinstraesser L, Flak E, Witte B, et al. Pressure garment therapy alone and in combination with silicone for the prevention of hypertrophic scarring: randomized controlled trial with intraindividual comparison. Plast Reconstr Surg. 2011;128:306e-313e. PMID: 21921743 DOI: 10.1097/ PRS.0b013e3182268c69

7. O'Brien L, Jones DJ. Silicone gel sheeting for preventing and treating hypertrophic and keloid scars. Cochrane Database Syst Rev. 2013;9:CD003826. PMID: 24030657 DOI: 10.1002/14651858.CD003826.pub3

8. Donelan MB. In: Thorne $\mathrm{CH}$, ed. Principles of Burn Reconstruction: Grabb and Smith's Plastic Surgery. 6th ed. Philadelphia, PA: Lippincott Williams \&Wilkins; 2007. p. 15061.

9. Gauglitz GG, Korting HC, Pavicic T, Ruzicka T, Jeschke MG. Hypertrophic scarring and keloids: pathomechanisms and current and emerging treatment strategies. Mol Med. 2011;17(12):113-25. PMID: 20927486 PMCID: PMC3022978 DOI: 10.2119/molmed.2009.00153

10. Oliaei S, Nelson JS, Fitzpatrick R, Wong BJ. Laser treatment of scars. Facial Plast Surg. 2012;28(5):518-24. PMID:23027219 DOI: $10.1055 / \mathrm{s}-0032-1325646$

11. Oh BH, Hwang YJ, Lee YW, Choe YB, Ahn KJ. Skin characteristics after fractional photothermolysis. Ann Dermatol. 2011;23(4):448-54. PMID: 22148011 PMCID: PMC3229937 DOI: $10.5021 / \mathrm{ad} .2011 .23 .4 .448$

12. Kim HS, Lee JH, Park YM, Lee JY. Comparison of the effectiveness of nonablative fractional laser versus ablative fractional laser in thyroidectomy scar prevention: a pilot study. J Cosmet Laser Ther. 2012;14(2):89-93. PMID: 22409153 DOI: 10.3109/14764172.2012.672746

13. Anderson RR, Donelan MB, Hivnor C, Greeson E, Ross EV, Shumaker PR, Uebelhoer NS, Waibel JS. Laser Treatment of Traumatic ScarsWith an Emphasis on Ablative Fractional Laser Resurfacing Consensus Report. JAMA Dermatology. 2014; 150(2):187-93. PMID: 24336931 DOI: 10.1001/ jamadermatol.2013.7761

14. Donelan MB, Parrett BM, Sheridan RL. Pulsed Dye Laser Therapy and Z-Plasty for Facial Burn Scars: The Alternative to Excision. Annals of Plastic Surgery. 2008;60(5):480-6. PMID: 18434818 DOI: $10.1097 /$ SAP.0b013e31816fcad5

15. Baryza MJ, Baryza GA. The Vancouver Scar Scale: an administration tool and its interrater reliability. J Burn Care Rehabil. 1995 Sep-Oct;16(5):535-8.

16. Manstein D, Herron GS, Sink RK, Tanner H, Anderson RR. Fractional photothermolysis: a new concept for cutaneous remodeling using microscopic patterns of thermal injury. Lasers Surg Med. 2004;34(5):426-38. PMID: 15216537 DOI: 10.1002/ $1 \mathrm{sm} .20048$

17. Żądkowski T, Nachulewicz P, Mazgaj M, et al. A new CO2 laser technique for the treatment of pediatric hypertrophic burn scars: An observational study. Medicine (Baltimore). 2016;95(42):e5168. PMID: 27759650 PMCID: PMC5079334 DOI: $10.1097 / \mathrm{MD} .0000000000005168$

18. Hultman CS, Friedstat JS, Edkins RE, Cairns BA, MD, Meyer AA. Laser Resurfacing and Remodeling of Hypertrophic Burn Scars. The Results of a Large, Prospective, Before-After Cohort Study, With Long-term Follow-up. Ann Surg. 2014;260(3):51932. PMID: 25115428 DOI: 10.1097/SLA.0000000000000893

19. Issler-Fisher AC, Fisher OM, Smialkowski AO, Frank Li, Schalkwyk CP, Haertsch P, Maitz PKM. Ablative fractional $\mathrm{CO} 2$ laser for burn scar reconstruction: An extensive subjective and objective short-term outcome analysis of a prospective treatment cohort. Burns. 2017;42:573-82. PMID: 27707636 DOI: 10.1016/j.burns.2016.09.014

20. Levi B, Ibrahim A, Mathews K, Wojcik B, Gomez J, Fagan $\mathrm{S}$, Austen WG Jr, Goverman J. The Use of $\mathrm{CO} 2$ Fractional Photothermolysis for the Treatment of Burn Scars. J Burn Care Res. 2016 Mar-Apr;37(2):106-14. PMID: 26536539 DOI:10.1097/BCR.0000000000000285

21. El-Zawahry BM, Sobhi RM, Bassiouny DA, Tabak SA. Ablative $\mathrm{CO} 2$ fractional resurfacing in treatment of thermal burn scars: an open label controlled clinical and histopathological study. J Cosmet Dermatol. 2015;14:324-31. PMID: 26260018 DOI: 10.1111/jocd. 12163

22. Lee SJ, Yeo IK, Kang JM, Chung WS, Kim YK, Kim BJ, Park KY. Treatment of Hypertrophic Burn Scars by Combination Laser-Cision and Pinhole Method Using a Carbon Dioxide laser. Lasers Surg Med. 2014;46:380-4. PMID: 24729387 DOI: 10.1002/1sm.22247

23. Willows BM, Ilyas M, Sharma A. Laser in the management of burn scars. Burns. 2017;43:1379-89. PMID: 28784339 DOI: 10.1016/j.burns.2017.07.001

24. Bailey JK, Burkes SA, Visscher MO, et al. Multimodal Quantitative Analysis of Early Pulsed-Dye Laser Treatment of Scars at a Pediatric Burn Hospital. Dermatologic Surgery. 2012;38(9):1490-1496. PMID: 22672578 DOI: 10.1111/j.15244725.2012.02451.x. 